\title{
METODOLOGIA DE AVALIAÇÃO DA AGRESSIVIDADE DE ISOLADOS DE Sphaeropsis sapinea A Pinus taeda
}

\author{
Paula Rachel Rabelo Corrêa ${ }^{1}$, Celso Garcia Auer ${ }^{2}$, Álvaro Figueredo dos Santos ${ }^{2}$, Antonio Rioyei Higa ${ }^{3}$ \\ ${ }^{1}$ Bióloga, M.Sc., Doutoranda em Eng. Florestal, UFPR, Curitiba, Paraná, Brasil - pbasilio@ufpr.br \\ ${ }^{2}$ Eng. Florestal, Dr., EMBRAPA Florestas, Colombo, Paraná, Brasil - auer@cnpf.embrapa.br; alvaro@cnpf.embrapa.br \\ ${ }^{3}$ Eng. Florestal, Dr., Depto. de Ciências Florestais, UFPR, Curitiba, Paraná, Brasil - higa @ufpr.br \\ Recebido para publicação: 06/02/2009 - Aceito para publicação: 23/08/2010
}

\begin{abstract}
Resumo
Sphaeropsis sapinea é conhecido como importante patógeno em Pinus, causando seca de ponteiros e morte de árvores em plantios comerciais. No Brasil, o primeiro relato da ação de $S$. sapinea ocorreu na década de 1940, durante introdução de Pinus radiata no estado de São Paulo, dizimando totalmente os plantios. Com o objetivo de selecionar material genético resistente a essa doença no Brasil, desenvolveuse uma metodologia para avaliar a agressividade de isolados de S. sapinea em frutos de maçã e Pinus taeda. Três ambientes (estufas com diferentes regimes de irrigação), dois métodos de inoculação (com e sem injúria) e três métodos de reisolamento do fungo (meio BDA, câmara úmida em saco plástico e em gerbox úmido) foram testados. Resultados mostraram diferenças significativas $(\mathrm{p}<0,05)$ na agressividade dos isolados em frutos de maçã e em mudas de $P$. taeda. O melhor método de reisolamento foi a câmara úmida e o melhor ambiente para a incubação de mudas de $P$. taeda foi em estufa coberta com lona plástica, com duas aspersões diárias de 4 minutos. Outro resultado foi que injúria é necessária para inoculação de $S$. sapinea. Os resultados da caracterização mostraram diferenças significativas na agressividade e diversidade genética do patógeno em todos os hospedeiros testados.

Palavras-chave: Fungo; inoculação; melhoramento genético; Pinus.
\end{abstract}

\begin{abstract}
Evaluation methodology of the aggressiveness of isolated of Sphaeropsis sapinea on Pinus taeda. Sphaeropsis sapinea is known as an important pathogen of Pinus, causing tip blight and death of trees in commercial plantings. In Brazil, the first report of this disease was done in the 1940s, during introduction of Pinus radiata in São Paulo State, when these plantations were destroyed by S sapinea. In order to select material resistant to such disease in Brazil, a methodology was developed to evaluate aggressiveness in S. sapinea isolates on apple fruits and Pinus taeda. Three environments (greenhouse with different regimes of irrigation), two inoculation methods (with and without injury) and three methods of re-isolation of fungus (PDA medium, moist chamber in plastic bags and moist gerbox) had been tested. Results pointed to significant differences $(\mathrm{p}<0,05)$ on aggressiveness in apple fruit and $P$. taeda seedlings. The better method to re-isolate was moist chamber in plastic bags and the better environment to incubate inoculated seedlings was greenhouse with two diary aspersion of four minutes. Other result was that injury is necessary for a good inoculation of $S$. sapinea. The characterization results have presented significant differences in relation to aggressiveness and genetic diversity of the pathogen in all tested hosts.
\end{abstract}

Keywords: Breeding; fungus; inoculation; Pinus.

\section{INTRODUÇÃO}

O gênero Pinus vem sendo plantado em escala comercial, no Brasil, há mais de 30 anos. Os plantios mais extensos foram estabelecidos na região Sul e Sudeste, para atender demanda de matériaprima de qualidade nas indústrias de celulose, papel, madeira serrada, resina e MDF, e até mesmo no aproveitamento como biomassa para geração de vapor e energia. Esse gênero apresenta uma boa adaptação para as condições edafoclimáticas brasileiras, dependendo o seu sucesso da escolha correta da espécie, da área selecionada para o seu estabelecimento e do manejo correto dos plantios (SHIMIZU; MEDRADO, 2005). 
Novas introduções de diversas espécies do gênero Pinus estão ocorrendo, inclusive nas regiões tropicais, e o plantio está se expandindo para todo o Brasil. O estabelecimento de florestas plantadas com Pinus, quando bem manejadas, está abastecendo o mercado com matéria-prima que até muito pouco tempo atrás era suprido pela floresta nativa, como, por exemplo, a araucária (SHIMIZU; MEDRADO, 2005). Para as indústrias de papel e celulose, os plantios de Pinus são muito importantes, uma vez que contribuem com as fibras longas, imprescindíveis na fabricação de papéis que exigem maior resistência e melhor absorção de tinta (BARRICHELO et al., 1977). Para suprir essa demanda, Pinus radiata D. Don foi a espécie escolhida em todo o mundo, principalmente no hemisfério Sul. O interesse por essa espécie decorre das qualidades técnicas da sua madeira, muito apreciada pela indústria de celulose, devido às características anatômicas das suas fibras, que são mais compridas, em relação a outras coníferas (CLAPP, 1995). Por ser fácil de serrar e trabalhar, é também muito procurada pela indústria moveleira, possuindo uma ampla aceitação internacional nesse mercado (REMADE, 2003).

Muitas são as doenças que atacam as espécies desse gênero, causando sérios prejuízos nos plantios comerciais no Brasil e no mundo. Entre essas doenças, a seca de ponteiro ou "tip blight" é considerada uma das mais graves, atacando plantios comerciais de Pinus em todo o mundo, inclusive o $P$. radiata, sendo seu controle e prevenção muito difíceis (AUER; GRIGOLETTI JÚNIOR, 1997). Essa dificuldade acontece porque muitos fatores podem estar envolvidos no aparecimento dos seus sintomas, inclusive vários patógenos atuando isoladamente ou de forma combinada, dificultando o seu diagnóstico. $\mathrm{Na}$ maioria dos casos, o principal patógeno envolvido com essa doença, nos Pinus, é o fungo Sphaeropsis sapinea (Fr.: Fr.) Dyko \& Sutton (= Diplodia pinea (Desmaz. J. Kickx f.), cuja principal característica é atacar os plantios depois de uma condição de estresse ambiental nas plantas hospedeiras, provocando a morte de mudas recentemente plantadas ou de plantios já estabelecidos (STANOSZ; CARLSON, 1996). Os sintomas provocados por esse patógeno incluem uma coloração (azulamento) na madeira interna, acículas queimadas e pontos pretos azulados nos brotos novos e nas hastes (STANOSZ; CARLSON, 1996; BLODGETT; STANOSZ, 1999). Esses sintomas podem não ser diferenciados de outros provocados por outros patógenos e insetos, por isso o diagnóstico requer o reconhecimento de corpos de frutificação do $S$. sapinea nas hastes ou nas raízes afetadas, ou crescimento do fungo em culturas, no laboratório (STANOSZ; CARLSON, 1996). O controle químico do S. sapinea no viveiro e em plantações não é efetivo, porque o fungo permanece latente nos brotos mesmo após a sua aplicação, segundo Stanosz et al. (1997).

Um importante passo que pode fornecer medidas mais eficientes para o controle da doença é a seleção de indivíduos com diferentes níveis de resistência ao patógeno. Mas, antes de se realizar essa seleção, é importante o conhecimento dos diferentes graus de agressividade do fitopatógeno, pois variedades de plantas suscetíveis inoculadas com isolados do fungo que apresentam baixa agressividade poderão mostrar-se, falsamente, muito resistentes (CASSIOLATO; MELLO, 1994).

$\mathrm{O}$ teste com frutos de maçã é utilizado para avaliar a agressividade entre isolados e caracterizar os diferentes morfotipos de S. sapinea. Os isolados de $S$. sapinea manifestam de forma bem diferente sua agressividade em frutos de maçã, sendo que o morfotipo C é o mais agressivo (De Wet et al., 2002).

No Brasil, são escassos os trabalhos com esse fungo e as reações que eles provocam em plantas de Pinus, não existindo, também, trabalhos dirigidos à seleção de variedades resistentes a esse patógeno. Segundo Burdon et al. (1982), a seleção de indivíduos resistentes e adaptados às condições locais é um importante método de controle de doença provocada pelo $S$. sapinea. Portanto, é possível desenvolver uma metodologia para seleção precoce de $P$. radiata resistente à $S$. sapinea, utilizando-se isolados agressivos desse patógeno.

Este estudo visou caracterizar a agressividade de diferentes isolados do fungo $S$. sapinea em frutos de maçã e em mudas de $P$. taeda, sob diferentes ambientes e métodos de inoculação, com o objetivo de estabelecer um protocolo de inoculação para ser usado em seleção para material resistente de $P$. radiata.

\section{MATERIAL E MÉTODOS}

Avaliação da agressividade de isolados de $S$. sapinea em frutos de maçã

A agressividade dos isolados de $S$. sapinea foi inicialmente testada usando-se a técnica de inoculação em frutos de maçã. Essa técnica foi utilizada por De Wet et al. (2002) em frutos de maçã para 
caracterizar os morfotipos de $S$. sapinea. Os isolados SS 1 (São José do Ouro/PR), SS 2 (Rancho Queimado/SC), SS 3 (Santa Maria do Oeste/PR) e SS 4 (Curitiba/PR) foram cultivados em placas com meio BDA, mantidos em câmara BOD a $25{ }^{\circ} \mathrm{C}$ por quatro dias de crescimento ativo, para produção de inóculos (discos de micélio-ágar). Cada fruto foi desinfestado com álcool 70\%, por aproximadamente 30 segundos. Furadores de cortiça foram usados para fazer um orifício de $5 \mathrm{~mm}$ de diâmetro em um dos lados do fruto. Um disco de micélio foi colocado em cada orifício, que foi recoberto com fita de PVC. Como testemunha, utilizou-se disco de meio BDA sem micélio. Cada isolado foi inoculado em três frutos, com cinco repetições, em delineamento inteiramente casualizado. Os frutos foram mantidos por duas semanas em câmara BOD, a $25{ }^{\circ} \mathrm{C}$, no escuro. Foram realizadas duas medições, uma aos sete dias após a inoculação (DAI) e outra medição aos 14 DAI. Com auxílio de uma régua, foram medidos dois diâmetros perpendiculares da lesão formada no fruto. Os dados foram analisados estatisticamente (ANOVA) e as médias foram comparadas pelo teste de Duncan (Software Statistica, StatSoft, 2001).

Avaliação do efeito do tipo de regime hídrico e de inoculação na agressividade de isolados de $S$. sapinea em mudas de $P$. taeda

O ensaio foi realizado em viveiro do Laboratório de Melhoramento Florestal (LAMEF) da UFPR, Curitiba, PR. O viveiro é recoberto por sombrite (75\% de passagem de luz solar), numa área de $12 \mathrm{~m}$ x $20 \mathrm{~m}$, dentro da qual estão localizadas duas estufas agrícolas de $6 \mathrm{~m} \times 4 \mathrm{~m}$, estruturadas por tubos de PVC com 5,5 cm de diâmetro e $6 \mathrm{~m}$ de comprimento, recobertas com lona plástica transparente. A terceira estufa estava recoberta somente com sombrite. $\mathrm{O}$ monitoramento dos ambientes foi realizado medindo-se a quantidade de água diária de cada estufa, através de provetas. Na área coberta apenas pelo sombrite, a água da chuva foi coletada separadamente da água dos aspersores. A temperatura e a umidade dentro das estufas foram monitoradas diariamente, durante todo experimento, usando-se um Hobbo. Esse equipamento foi aferido periodicamente com o termômetro de máximo e mínimo, e a umidade com o uso de termômetro de bulbo seco e úmido.

Neste ensaio, três regimes hídricos foram escolhidos para determinar o mais favorável ao estabelecimento da doença. No ambiente 1, o regime foi de uma aspersão diária (às 8:00 h da manhã) com 4 minutos de duração. No ambiente 2, duas aspersões ao dia (às 9:00 e 17:00 h), com 4 minutos de duração cada aspersão. No ambiente 3 (sombrite), três aspersões ao dia (às 9:30, 12:00 e 18:00 h), com 20 minutos de duração cada aspersão. As mudas foram submetidas a uma condição de estresse hídrico antes da inoculação, sem molhamento por sete dias, segundo De Wet et al. (2002).

Os isolados de $S$. sapinea foram cultivados em meio BDA e transferidos para meio AA ( $20 \mathrm{~g}$ de ágar e água destilada, $1000 \mathrm{~mL}$ ) para produção do inóculo (disco de micélio-ágar). Para a inoculação, utilizaram-se discos de micélio-ágar retirados do meio AA com 10 dias de crescimento. Cada disco de meio AA, contendo ou não o fungo, foi fixado na planta com fita adesiva por quatro dias. As plantas inoculadas foram mantidas em ambiente úmido com água destilada, por $48 \mathrm{~h}$. Depois desse período, as mudas foram transferidas para as estufas e mantidas por cerca de 30 dias sob observação. Foram testados dois tipos de inoculação: com e sem injúria, feita com o corte das acículas e raspagem do ponteiro.

O ensaio foi montado em delineamento em blocos ao acaso com arranjo fatorial, num total de 864 plantas (12 isolados monospóricos, dois tipos de inoculação, três regimes hídricos, três repetições, duas plantas por parcela). Na avaliação da doença, mediu-se o comprimento da lesão com o auxílio de uma régua, a partir do ponto de inoculação (BLODGETT; STANOSZ, 1999). Dois métodos para avaliar a severidade foram empregados. No primeiro método, o comprimento da lesão foi avaliado de acordo com uma escala de severidade, que caracterizou a lesão como pequena $(0$ a $3 \mathrm{~cm})$, média $(4$ a $7 \mathrm{~cm})$ ou grande $(8$ a $10 \mathrm{~cm})$. No segundo método, avaliou-se o secamento do ponteiro de acordo com uma escala de severidade, em que 0 significou ausência de sintoma da doença, 1 para o início de lesão, 2 quando houve seca de ponteiro, 3 para seca de ponteiro sem anelamento, 4 para seca de ponteiro com anelamento e 5 para muda morta (BURDON et al., 1982). Os dados foram estatisticamente analisados (ANOVA) e as médias foram comparadas pelo teste de Duncan (Software Statistica, Statsoft, 2001).

\section{Avaliação do reisolamento de $S$. sapinea a partir de ponteiros de mudas de $P$. taeda}

Nesse ensaio, três metodologias para reisolamento do fungo foram testadas, conforme descrição em Basílio (2008). Na primeira metodologia, fez-se uma amostragem das mudas inoculadas de P. taeda. Essa amostragem foi feita através da coleta de material de cinco parcelas (duas plantas por parcela) em 
cada bandeja do experimento, para a realização do reisolamento em placas de Petri com meio BDA, mantidas em câmara BOD, a $25^{\circ} \mathrm{C}$. Na segunda metodologia, os ponteiros de todas as plantas inoculadas foram colocados em câmara úmida. Os ponteiros foram coletados após um mês de inoculação e mantidos em sacos plásticos individualizados, devidamente identificados. Na terceira metodologia, colocaram-se os ponteiros em câmara úmida dentro de caixas gerbox com papel de filtro esterilizado e umedecido com água destilada esterilizada.

Todo o material foi analisado semanalmente, por 30 dias. Após esse período, realizaram-se os exames dos ponteiros em microscópio estereoscópico e foram montadas lâminas coradas com solução de lactoglicerol - azul de metileno. As lâminas foram examinadas sob microscópio ótico em aumentos de 100x a 400x para confirmar a presença de conídios de $S$. sapinea.

\section{RESULTADOS E DISCUSSÃO}

\section{Avaliação da agressividade de isolados de $S$. sapinea em frutos de maçã}

Os isolados SS 1, SS 2, SS 3 e SS 4 de S. sapinea foram patogênicos nos frutos de maçã, formando extensas lesões. Houve diferença na agressividade entre os isolados testados (Tabela 1). Essas variações foram significativas pelo teste $\mathrm{F}(\mathrm{p}<0,05)$, aos sete e 14 DAI. Observou-se que aos sete DAI foi encontrado um coeficiente de variação alto (43\%), indicando dispersão entre os dados. A análise de variância, com os dados das medições aos 14 DAI, mostrou um valor de coeficiente de variação mais baixo (23,84\%), indicando menor erro experimental, motivo pelo qual se recomend que a leitura seja feita aos 14 dias.

O isolado SS 1 mostrou-se o mais agressivo, aos sete DAI e aos 14 DAI. Estudo similar realizado por De Wet et al. (2002) testou a agressividade de $S$. sapinea com a inoculação de três diferentes morfotipos (A, B, C) em frutos de maçã, encontrando-se diferenças significativas no tamanho das lesões. No geral, a área de lesão produzida pelos isolados do morfotipo C $\left(24 \mathrm{a} 655 \mathrm{~mm}^{2}\right)$ foram significativamente maiores que as produzidas pelos isolados dos morfotipos A (24 a $\left.553 \mathrm{~mm}^{2}\right)$ e B (21 a $116 \mathrm{~mm}^{2}$ ). Segundo esses autores, o teste de patogenicidade em frutos de maçã é eficiente para avaliar a agressividade dos isolados de diversos fungos, inclusive de S. sapinea.

Tabela 1. Lesões $(\mathrm{cm})$ em frutos de maçãs inoculados com quatro isolados de Sphaeropsis sapinea.

Table 1. Lesions $(\mathrm{cm})$ in apple fruits inoculated with four isolates of Sphaeropsis. sapinea.

\begin{tabular}{lcc}
\hline \multirow{2}{*}{ Isolado } & \multicolumn{2}{c}{${\text { Tamanho da lesão }(\mathbf{c m})^{\alpha}}^{\alpha}$} \\
\cline { 2 - 3 } & $\mathbf{7 ~ D A I}^{\mathrm{b}}$ & $\mathbf{1 4} \mathbf{D A I}$ \\
\hline SS 1 & $4,84 \mathrm{a}$ & $7,93 \mathrm{a}$ \\
SS 2 & $3,46 \mathrm{~b}$ & $6,33 \mathrm{~b}$ \\
SS 3 & $3,17 . \mathrm{b}$ & $6,33 \mathrm{~b}$ \\
SS 4 & $3,89 \mathrm{~b}$ & $5,32 \mathrm{~b}$ \\
Testemunha & $1,43 \mathrm{c}$ & $1,48 \mathrm{c}$ \\
\hline P & 0,02 & 0,01 \\
\hline CV (\%) & 43,0 & 23,8 \\
\hline
\end{tabular}

${ }^{\alpha}$ Valores correspondem à média de 5 repetições por isolado. Médias seguidas pela mesma letra não diferem pelo teste de Duncan ao nível de significância de 5\%. ${ }^{\mathrm{b}}$ DAÎ́: dias após inoculação.

A diferença na agressividade dos isolados é um indicativo de divergências genéticas entre eles. De Wet et al. (2000) descreveram dois morfotipos inicialmente para S. sapinea (A e B), com base nas características das culturas, textura da parede dos conídios, confirmados através do uso de ferramentas moleculares, como RAPD e sequenciamento da região ITS do RNA operon. Os autores relataram também um terceiro grupo, denominado morfotipo $\mathrm{C}$, obtido do México e Indonésia, com base nas medidas conidiais e marcadores RAPD. Burgess et al. (2001) reconheceram três formas de S. sapinea, que diferem entre si morfologicamente e que podem ser separadas por meio de ferramentas moleculares. Para esses estudos, os autores coletaram populações de $S$. sapinea de plantações de $P$. radiata na África do Sul, no sul e noroeste da Austrália, na Tasmânia, na Nova Zelândia e de populações nativas na Califórnia. A diversidade genotípica dessas populações foi marcada e comparada com testes de compatibilidade vegetativa. Marcadores SSR foram usados para determinar os morfotipos dos isolados de cada grupo de compatibilidade vegetativa encontrado. Todos os isolados de S. sapinea obtidos da Califórnia eram do morfotipo B, menos agressivos, enquanto que todos os isolados obtidos de plantações exóticas eram do 
morfotipo A, mais agressivo. Em trabalho semelhante, De Wet et al. (2003) identificaram três morfotipos (A, B e C), que foram caracterizados com 6 pares de primers SSR, e comprovaram que o morfotipo B, menos agressivo, apresentou menor divergência genética em relação aos morfotipos A e C, que são mais agressivos.

Avaliação do efeito do tipo de regime hídrico e de inoculação na agressividade de isolados de $S$. sapinea em mudas de $P$. taeda

A análise dos dados mostrou diferenças significativas $(\mathrm{p}<0,05)$ com relação à agressividade dos diversos isolados inoculados em mudas de P. taeda (Tabela 2). O isolado monospórico SS 2.4 foi o mais agressivo em mudas de $P$. taeda, seguido pelos isolados SS 4.10 e SS 1.3, os quais podem ser selecionados para os testes de agressividade e de seleção para resistência.

Os resultados mostraram também que o método de inoculação 1 (com fungo e com injúria) foi o mais eficaz em induzir os sintomas (Tabela 2). Quanto ao regime hídrico nas estufas, pode-se verificar que o melhor ambiente para o desenvolvimento de sintomas induzidos por $S$. sapinea foi em túnel com duas aspersões diárias (Tabela 2).

Tabela 2. Lesões (cm) em ponteiros de Pinus taeda inoculados com isolados de Sphaeropsis sapinea, sob quatro métodos de inoculação.

Table 2. Lesions (cm) in Pinus taeda shoots inoculated with isolated of Sphaeropsis sapinea under four inoculation methods.

\begin{tabular}{lccccc}
\hline \multirow{2}{*}{ Isolado monospórico } & \multicolumn{5}{c}{ Método de inoculação } \\
\cline { 2 - 6 } & M1 $^{\mathbf{a}}$ & M2 & M3 & M4 & Médias \\
\hline SS 2.4 & $8,42^{\mathrm{b}}$ & 1,33 & 0,00 & 0,00 & $2,44 \mathrm{a}$ \\
SS 4.10 & 7,22 & 1,11 & 0,00 & 0,00 & $2,08 \mathrm{a}$ \\
SS 1.3 & 6,89 & 0,33 & 0,00 & 0,00 & $1,81 \mathrm{a}$ \\
SS 1.1 & 6,06 & 0,61 & 0,00 & 0,50 & $1,79 \mathrm{ab}$ \\
SS 4.12 & 6,44 & 0,11 & 0,00 & 0,00 & $1,64 \mathrm{bc}$ \\
SS 2.5 & 3,78 & 0,00 & 0,44 & 0,00 & $1,06 \mathrm{bcd}$ \\
SS 3.7 & 3,33 & 0,39 & 0,00 & 0,00 & $0,93 \mathrm{bcd}$ \\
SS 3.8 & 2,83 & 0,61 & 0,00 & 0,00 & $0,86 \mathrm{bcd}$ \\
SS 2.6 & 2,33 & 0,67 & 0,00 & 0,00 & $0,75 \mathrm{~cd}$ \\
SS 4.11 & 2,5 & 0,00 & 0,00 & 0,00 & $0,62 \mathrm{~d}$ \\
SS 1.2 & 0,61 & 0,00 & 0,00 & 0,00 & $0,15 \mathrm{~d}$ \\
SS 3.9 & 0,33 & 0,00 & 0,00 & 0,00 & $0,08 \mathrm{~d}$ \\
\hline Médias & $4,23 \mathrm{~A}$ & $0,43 \mathrm{~B}$ & $0,04 \mathrm{~B}$ & $0,04 \mathrm{~B}$ & \\
\hline
\end{tabular}

${ }^{a}$ M1: inoculação com injúria e com o fungo; M2: inoculação com injúria e sem o fungo; M3: inoculação com o fungo e sem injúria; M4: inoculação sem o fungo e sem injúria. Médias seguidas por letras minúsculas (na coluna) e maiúsculas (na linha) iguais não diferem significativamente entre si ( $\mathrm{p}<0,05$, Duncan). ${ }^{\mathrm{b}}$ Os valores são médias de dados obtidos em três ambientes estudados: túnel 1 (uma aspersão de 4 minutos/dia); túnel 2 (duas aspersões de 4 minutos/dia) e sombrite (20 minutos de aspersão, 3 vezes ao dia).

Houve variação na agressividade entre os isolados monospóricos obtidos de um dado isolado original, a exemplo das lesões produzidas pelos isolados SS 2.4, SS 2.5 e SS 2.6 (Tabela 2). Uma explicação para isso pode ser obtida a partir do trabalho de McDonald (1997), no qual foi evidenciado que a variabilidade do $S$. sapinea decorre da presença de linhagens clonais dentro de suas populações. Tal como no ensaio com maçãs, os resultados obtidos com as mudas de $P$. taeda também mostraram diferenças na agressividade dos isolados, que podem estar ligadas à divergência genética entre eles (DE WET et al., 2000).

A explicação de como essas diferenças na agressividade foram desenvolvidas e distribuídas entre as populações não está muito clara, uma vez que o $S$. sapinea se reproduz apenas assexuadamente. A variabilidade possível de se obter via reprodução assexuada é muito baixa e geralmente insuficiente para responder por tal divergência genética. Por outro lado, as linhagens clonais são comuns em fungos que se reproduzem apenas assexuadamente (McDONALD, 1997).

\section{Avaliação do reisolamento de $S$. sapinea a partir de ponteiros de mudas de $P$. taeda}

Os resultados mostraram que a metodologia de isolamento direto em câmara úmida (saco plástico ou gerbox) foi mais eficiente e que o plaqueamento foi menos eficaz em reisolar o fungo 
(Tabela 3). O isolamento por plaqueamento foi o primeiro método a ser testado, mas após sucessivas avaliações ficou claro que esse método não estava sendo eficiente para avaliar o experimento. Uma explicação é a contaminação com outros fungos e bactérias que surgem a partir dos fragmentos em meio de cultura, os quais competem com $S$. sapinea e mascaram o reisolamento.

Tabela 3. Reisolamento de Sphaeropsis sapinea de mudas inoculadas de Pinus taeda, sob três diferentes métodos de reisolamento.

Table 3. Reisolation of Sphaeropsis sapinea from inoculated Pinus taeda seedlings, under three different methods of reisolation.

\begin{tabular}{|c|c|c|c|c|c|c|}
\hline \multirow{3}{*}{ Método de reisolamento } & \multicolumn{5}{|c|}{ Frequência de reisolamento (\%) } & \multirow{3}{*}{$\begin{array}{l}\text { Ponteiros } \\
\text { coletados }\end{array}$} \\
\hline & \multicolumn{4}{|c|}{ Tipo de inoculação ${ }^{a}$} & \multirow{2}{*}{ Total } & \\
\hline & 1 & 2 & 3 & 4 & & \\
\hline Câmara úmida em saco plástico & 12,8 & 1,7 & 0,0 & 0,0 & 16,2 & 360 \\
\hline Câmara úmida e gerbox & 30,0 & 25,0 & 0,0 & 0,0 & 55,0 & 20 \\
\hline Plaqueamento em meio BDA & 1,7 & 0,8 & 0,0 & $0,8^{\mathrm{b}}$ & 3,3 & 360 \\
\hline
\end{tabular}

a Inoculação: tipo 1 (com injúria, com fungo); tipo 2 (com injúria, sem fungo); tipo 3 (sem injúria, com fungo); tipo 4 (sem injúria, sem fungo). ${ }^{b}$ resultado indicando endofitismo do fungo.

O reisolamento efetuado por câmara úmida (saco plástico) foi o mais prático e, por ter apresentado um bom resultado entre os testados, pode ser recomendado. É importante ressaltar que, em todos os métodos avaliados neste experimento, a frequência de reisolamento de $S$. sapinea foi baixa a partir de lesões em ponteiros em mudas de $P$. taeda.

Em alguns ponteiros com lesões, o fungo $S$. sapinea não foi reisolado por nenhum dos métodos utilizados, e em outras situações, o fungo foi reisolado de ponteiros que não foram inoculados e não apresentaram lesões (Tabela 3). A explicação para esse fato pode ser encontrada no trabalho de Stanosz et al. (1997), no qual os autores indicaram a possibilidade de o fungo já estar presente como endófito em plantas de Pinus. Microrganismos endofíticos são encontrados no interior de vegetais, mantendo uma relação simbiótica, antagonista ou mesmo neutra (AZEVEDO, 1998), sendo capazes de colonizar, em alguma fase de seu ciclo de vida, os tecidos internos dos vegetais sem causar danos aparentes. Como endofítico, o fungo está em seu estado latente e somente se a planta ficar estressada é que os sintomas de doenças poderão aparecer (STANOSZ; CARLSON, 1996). Burgess et al. (2004) comentaram que, como endófito, provavelmente $S$. sapinea foi disseminado pelo mundo juntamente com as introduções de mudas de Pinus. Com base nessa hipótese, $S$. sapinea pode ter sido introduzido no Brasil a partir de mudas com infecções latentes, durante as primeiras introduções de Pinus.

\section{CONCLUSÕES}

Os isolados de $S$. sapinea mostraram diferenças significativas ( $<<0,05$ ) na agressividade quando inoculados em frutos de maçã e no teste de agressividade em mudas de $P$. taeda, sob diferentes ambientes. O melhor ambiente para o desenvolvimento da doença foi em túnel plástico sob regime de duas aspersões diárias com quatro minutos de duração cada. $\mathrm{O}$ método de inoculação mais eficiente em mudas de $P$. taeda foi com injúria no ponteiro, e o método de reisolamento mais eficaz e mais prático foi por câmara úmida (saco plástico).

\section{REFERÊNCIAS}

AUER, C. G.; GRIGOLETTI, J. A. Ocorrência do fungo Sphaeropsis sapinea em Pinus nos estados do Paraná e de Santa Catarina. Boletim de Pesquisa Florestal, Colombo, v. 34, p. 99 - 101, 1997.

AZEVEDO, J. L. Microrganismos endofíticos. In: MELO, I. S.; AZEVEDO, J. L. (coords.). Ecologia microbiana. Jaguariúna: Embrapa CNPMA, 1998. p. 117 - 137.

BARRICHELO, L. E. G.; KAGEYAMA, P. Y.; SPELTZ, R. M.; BONISH, J. H.; BRITO, J. O.; FERREIRA, M. Estudo de procedências de Pinus taeda visando o seu aproveitamento industrial. IPEF, Piracicaba, n. 15, p. 1 - 14, 1977. 
BASÍLIO, P. R. C. Caracterização de isolados de Sphaeropsis sapinea e avaliação de resistência de progênies de Pinus radiata. 98 f. Dissertação (Mestrado em Engenharia Florestal) - Universidade Federal do Paraná, Curitiba, 2008.

BLODGETT, J. T.; STANOSZ, G. R. Differences in aggressiveness of Sphaeropsis sapinea RAPD marker group isolates on several conifers. Plant Disease, Saint Paul, v. 83, n. 9, p. 853 - 856, 1999.

BURDON, R. D.; CURRIE, D.; CHOU, C. K. S. Responses to inoculation with Diplodia pinea in progenies of apparently resistant trees of Pinus radiata. Australasian Plant Pathology, Collingwood, v. 11, n. 4, p. 37 - 38, 1982.

BURGESS, T. I.; WINGFIELD, B. D.; WINGFIELD, M. J. Comparison of genotypic diversity in nature and introduced populations of Sphaeropsis sapinea isolated from Pinus radiata. Mycological Research, Cambridge, v. 105, n. 11, p. 1331 - 1339, 2001.

BURGESS, T. I.; GORDON, T. R.; WINGFIELD, M. J.; WINGFIELD, B. D. Geographic isolation of Diplodia scrobiculata and its association with native Pinus radiata. Mycological Research, Cambridge, v. 108, n. 12, p. 1399 - 1406, 2004.

CASSIOLATO, A. M. R.; MELO, I. S. de. Reação de resistência de genótipos de tomateiro (Lycopersicum spp.) à infecção por Rhizoctonia solani Kuhn. Scientia Agrícola, Piracicaba, v. 51, n. 3, p. 446 - 452, 1994.

CLAPP, R. A. Creating competitive advantage: forest policy an industrial policy in Chile. Economic Geography. Worcester, v. 71, n. 3, p. 273 - 296. 1995.

DE WET, J.; WINGFELD, M. J.; COUTINHO, T. A.; WINGFELD, B. D. Characterization of Sphaeropsis sapinea isolates from South Africa, Mexico and Indonesia. Plant Disease, Saint Paul, v. 84, n. 2, p. $151-156,2000$.

DE WET, J.; WINGFIELD, M. J.; COUTINHO, T. A.; WINGFIELD, B. D. Characterization of "C" morphotype of the pine pathogen Sphaeropsis sapinea. Forest Ecology and Management, Amsterdam, v. 161 , n. $1 / 3$, p. $181-188,2002$.

DE WET, J.; BURGESS, T.; SLIPPERS, B.; PREISIG, O.; WINGFIELD, B. D.; WINFIELD, M. J. Multiple gene genealogies and microsatellite markers reflect relationships between morphotypes of Sphaeropsis sapinea and distinguish a new species of Diplodia. Mycological Research, Cambridge, v. 107 , n. 5, p. 557 - 566, 2003.

McDONALD, B. A. The population genetics of fungi: tools and techniques. Phytopathology, Saint Paul, v. 87, n. 4 , p. 448 - 453, 1997.

REMADE - Chile conquista o exterior com Pinus radiata. Revista da Madeira, Curitiba, n. 70, 2003.

SHIMIZU, J. Y.; MEDRADO, M. J. S. Cultivo de Pinus. 2005. Disponível em <http://sistema producao.cnptia.embrapa.br>. Acesso em: 7/11/2007.

STANOSZ, G. R.; CARLSON, J. C. Association of mortality of recently planted seedlings and established saplings in red pine plantations with Sphaeropsis collar rot. Plant Disease, Saint Paul, v. 80, n. 7, p. 750 - 753, 1996.

STANOSZ, G. R.; SMITH, D. R.; GUTHMILLER, M. A.; STANOSZ, J. C. Persistence of Sphaeropsis sapinea on or in asymptomatic shoots of red and jack pine. Mycology, New York, v. 89, n. 4, p. 525 - 530, 1997.

STATSOFT, Inc. (2001). STATISTICA (Data analysis software system), version 6. Disponível em: $<$ http//: www.statsoft.com>.

FLORESTA, Curitiba, PR, v. 41, n. 2, p. 347-354, abr./jun. 2011. 
FLORESTA, Curitiba, PR, v. 41, n. 2, p. 347-354, abr./jun. 2011. Corrêa, P. R. R.; Auer, C. G.; Santos, A. F. dos; Higa, A. R. 